\title{
Solvency Runs, Sunspot Runs, and International Bailouts*
}

\author{
Mark M. Spiegel ${ }^{\dagger}$
}

March 21, 2000

\begin{abstract}
This paper introduces a model of international lender of last resort (ILLR) activity under asymmetric information. The ILLR is unable to distinguish between runs due to debtor insolvency and those which are the result of pure sunspots. Nevertheless, the ILLR can elicit the underlying state of nature from informed creditors by offering terms consistent with generating a separating equilibrium. Achieving the separating equilibrium requires that the ILLR lends to the debtor at sufficiently high rates. This adverse selection problem provides an alternative rationale for Bagehot's Principle of last-resort lending at high rates of interest to the moral hazard motivation commonly found in the literature.
\end{abstract}

\section{J.E.L. Classification Number: F34, G2}

Keywords: International lender of last resort, financial crises, foreign debt

\footnotetext{
*Send correspondence to Mark M. Spiegel, Economic Research, Federal Reserve Bank of San Francisco, 101 Market St., San Francisco, CA, 94105, mark.spiegel@sf.frb.org, (415)-974-3241.

${ }^{\dagger}$ Helpful comments were received from seminar participants at U.C. Davis and the Federal Reserve Bank of San Frnacisco. Hiroshi Kokame provided excellent research assistance. Opinions in this paper are the author's own, and do not necessarily reflect those of the Federal Reserve Bank of San Francisco or the Board of Gvoernors of the Federal Reserve.
} 


\section{Introduction}

In the wake of the Mexican peso and Asian financial crises of the 1990s, a large literature has emerged which attempts to explain crises as arising out of "selffulfilling prophecies," i.e. as crises which could have arisen at any time due to a change in investor beliefs. Most of these models [e.g. Goldfajn and Valdes (1997), Chang and Velasco (1999,2000), Freixas, Parigi and Rochet (2000)] build on the Diamond and Dybvig (1983) bank run model in characterizing international currency crises as stemming from liquidity shortages. In these models, foreign investors stage a "run" on a country, similar to a bank run, which results in the costly liquidation of investment and leaves default a self-fulfilling prophesy. ${ }^{1}$

A more recent literature has applied this framework to the question of the merits of an international lender of last resort (ILLR). Rodrik and Velasco (1999) introduce a model in which liquidity crises arise among short-term creditors refusing to roll over their claims, resulting in costly liquidation of long-term investment. Their model identifies short-term debt as an undesirable source of instability and begs the question of ILLR intervention to address this coordination failure. Jeanne (2000), Kumar, Masson and Miller (2000) and Goodhart and Huang (2000) explicitly consider the role for ILLR activity in the event of a liquidity crisis. Jeanne demonstrates that global welfare is increased through ILLR intervention in his model .

\footnotetext{
${ }^{1}$ Bank runs exist as pure sunspot phenomena in the Diamond-Dybvig model. A bank may be solvent, in the sense that it possesses adequate funds to support liquidity needs, but the combination of costly liquidation and the sequential service contraint imply that if depositors perceive a run on a bank it is in their interest to withdraw their funds as well. In contrast, Jacklin and Bhattacharya (1988) and Chari and Jagannathan (1988) examine a situation where runs are attributable to asymmetric information concerning the fundamentals among depositors. In these papers, uninformed depositors may (correctly or incorrectly) interpret a withdrawal by an informed agent as an adverse signal about the bank's fundamentals.
} 
ILLR activity tends to do well in these models because the crises considered are pure liquidity crises, and are idenitifiable as such. ${ }^{2}$ As a result, the ILLR knows that the nation to which it extends funds will recover with adequate liquidity provision. In this literature, ILLR activity is cast in the role of addressing a coordination failure generated by the bad sunspot equilibrium.

Allen and Gale (1998) demonstrate that under common knowledge a role for Pareto-improving intervention in bank runs only arises when a sufficient deadweight loss is created during liquidation.

However, the notion that a lender of last resort, either domestic or international, can readily ascertain whether a problem bank or nation is actually insolvent or just illiquid has been criticized [e.g. Goodhart (1999)]. Goodhart notes that with a small number of exceptions "...illiquidity implies at least a suspicion of insolvency," and suggests that the timely response required in lender of last resort lending precludes any possibility of ascertaining the underlying condition of a problem bank or nation.

The notion that runs on a nation may be solvency-based, rather than the result of pure sunspots, begs the question of an information asymmetry between the ILLR and the nation's creditors. Creditors can only stage a fundamentalsbased run if they are aware of bad fundamentals prevailing in the debtor nation. However, if the ILLR also had knowledge of the underlying fundamentals, it would be free to respond to the two types of runs optimally, as there would be no signal extraction problem to address.

This paper takes the possibility of fundamentals-based, or "solvency runs,"

\footnotetext{
${ }^{2}$ Both Kumar, et al (2000) and Goodhart and Huang (2000) raise the possibility of fundamentals based runs in addition to sunspot runs. Kumar, et al consider the merits of policies to discourage short-term debt. Goodhart and Huang consider ILLR activity in situations where there is a positive probability of an insolvency run. However, neither model considers the information asymmetry issues analyzed below.
} 
seriously. I introduce a simple model where creditors enjoy an information advantage relative to the ILLR. In particular, creditors learn if the expected prospects for the representative debtor nation are good or bad. If prospects are bad, a solvency run takes place with certainty. If prospects are good, the realization of a sunspot parameter determines whether a run takes place anyway. This latter form of run can be considered a "liquidity run," because in the absence of outside intervention the debtor will be forced to liquidate her project, even though her underlying fundamentals are sound.

While creditors are aware of the realization of the prospects for the project, the ILLR is assumed to be able to observe only the presence or absence of a run. This extreme form of information asymmetry is maintained for analytical simplicity, but the qualitative results only require that creditors have superior information concerning the underlying fundamentals of the debtor to the ILLR. This condition is probably met in most lender of last situations, but is particularly easy to defend in an international context. ${ }^{3}$ While large banks typically specialize in the nations to which they lend, the ILLR is required to follow conditions in all countries. Moreover, the resources available to an international institution, such as the International Monetary Fund (IMF), for such surveillance activity are likely to be smaller than those available to large private banks.

I then introduce an ILLR which acts as a coordinator of a relending package to the representative creditor. The ILLR offers to take on a fixed share of the debtor's outstanding obligations at specified terms, in return for the representative creditor rolling over the remaining debt obligations at another specified contractual rate. Since the creditor is assumed to be competitive, he accepts any relending package which leaves him as well off as he would be under liquidation of the debtor's project.

\footnotetext{
${ }^{3}$ Within the United States, Berger, Davies and Flannery (2000) find that supervisory assessments of future bank holding company performance is inferior to that of bond rating agencies.
} 
Depending on the terms offered by the ILLR, we can obtain one of three classes of equilibria: One is a separating equilibrium, under which the creditor accepts the ILLR's terms in the good state, but rejects its terms in the bad state. The other two are pooling equilibria; one in which the debtor accepts the creditors terms regardless of the state of nature, and another in which the debtor refuses the ILLR's terms, again regardless of the state of nature.

The criterion by which the ILLR achieves the separating equilibria is through refraining from offering relending terms which are "too generous." In particular, the ILLR precludes creditors from accepting the relending package conditional on the project being bad by requiring sufficiently high returns on ILLR lending.

This result is interesting, because it mirrors the well-known Bagehot Principle of the ILLR lending freely at high rates of interest. However, the motivation for the ILLR charging high lending rates in this paper is completely independent of that found in the existing literature [e.g. Thornton (1802), Sleet and Smith (2000)]. A traditional concern surrounding lender of last resort activity is that the expectation of such activity will lead to moral hazard in initial lending practices. For example, Goodhart (1999) quotes the following passage from Thornton (1802) concerning the motivation for last resort lending at high interest rates:

It is by no means intended to imply, that it would become the Bank of England to relieve every distress which the rashness of country banks may bring upon them; the bank, by doing this, might encourage their improvidence...The relief should neither be so prompt and liberal as to exempt those who miconduct their business from all the natural consequences of their fault, nor so scanty and slow as deeply to involve the general interest. (Thornton 1802, p. 121)

In this paper, the motivation for charging high rates of interest in ILLR activity is to address an adverse selection problem, rather than moral hazard. By offering bailout terms consistent with the separating equilibrium, the ILLR induces creditors to accept relending packages in good states, but refuse them in 
bad states. In this manner, the ILLR avoids the "mistake" of lending into an insolvency situation.

Indeed, I demonstrate below that a separating equilibrium exists under which ILLR activity has no impact on first-period lending relative to no intervention at all. Under this strategy, moral hazard issues do not arise. In contrast, however, offering a relending package at terms which yield a pooling equilibrium with relending in all states necessarily creates moral hazard, which is manifested in the simple model below as causing a reduction in first-period lending rates. ${ }^{4}$

The role of adverse selection issues in bank regulatory policy has been investigated elsewhere in the literature. Aghion, Bolton, and Fries (1999) consider the problem faced by a bank regulator who suffers an information disadvantage relative to the bank manager concerning an individual bank's financial health. They design a bailout scheme which induces the manager to reveal the bank's true underlying condition, while minimizing regulatory costs. Their policy prescription is that regulatory policy should not be too strict, because a policy of immediate closure and dismissal would discourage the bank managers from revealing his bank's true condition. Instead, they prescribe a non-linear transfer schedule for the liquidation of bad loans. Marchesi and Thomas (1999) consider the case where national governments possess superior information concerning a country's willingness to undertake costly reforms relative to the IMF. They show that conditionality in rescheduling programs, by increasing the cost of borrowing without reform, can induce national governments to reveal their type.

One outcome of the strictest separating equilibria policies, and those which have the least influence on first period lending relative to no intervention, is that the ILLR expects to earn positive profits on its lender of last resort activity. This result mirrors recent experience in international bailouts, such as the United

\footnotetext{
${ }^{4}$ There are also other relending packages which yield separating equilibria and the potential for moral hazard. These are addressed in more detail below.
} 
States' assistance during the Mexican peso crisis. Again, the positive profits are required to make the relending terms sufficiently unattractive to private creditors that the relending package is refused when the debtor is truly insolvent.

The remainder of this paper is divided into seven sections: The following section introduces a simple two-period model of international solvency and sunspot runs with asymmtric information. Section 3 derives the terms under which private creditors would be willing to roll over their debt claims in good and bad states. Section 4 introduces the possibility of an ILLR bailout subject to a run, and determines the constraint faced by the ILLR in offering an acceptable relending package in good and bad states. Section 5 closes the model by determining first-period lending rates based on the expected response of the ILLR to a run. Section 6 conducts some simulations of the results. Section 7 concludes.

\section{A Simple Model with Asymmetric Information}

The model has two periods. At the beginning of the first period, the representative borrower must externally borrow funds to finance her fixed-sized project. Projects take both periods for full value completion; there is a penalty for early liquidation. For simplicity, I normalize the size of needed external funds to 1. Borrowers can borrow in the form of a short-term debt instrument, which comes due after one period.

There is assumed to be sovereign risk in the model, which is modeled as a minimum level that borrowers could obtain from defaulting on their outstanding debt obligations. For notational simplicity, I normalize this value to zero. While the value of this minimum does matter, in the sense that sovereign risk is increasing in this minimum level, there is no special significance to its being set to zero. This value merely simplifies the notation. ${ }^{5}$

\footnotetext{
${ }^{5}$ If the minimum level of consumption supported by sovereign risk exceeded the minimum
} 
The extensive form begins with the representative creditor, who determines the interest rate charged on debt. Let $r_{1}$ represent the interest rate charged on first-period lending. For simplicity, I assume that creditors face a 0 interest rate on their funds.

See Figure 1. There are two resolutions of uncertainty prior to the end of the first period. First, nature chooses whether projects are "good" or "bad." The probability that a project will be good is assumed to equal $\phi$, where $\phi \epsilon(0,1)$. The value of $\phi$ is assumed to be exogenous and known to all agents.

Projects are assumed to yield return $z, z \epsilon[0, \bar{z}]$ if invested to two-period completion. Let $G(\bullet)$ represent the cumulative distribution of $\widetilde{z}$, i.e. probability that $z \leq \widetilde{z}$ for a good project, and let $g(z)$ represent the probability density function of $z$ for good projects. I assume that $g(z)>0$ for all $z \epsilon[0, \bar{z}]$. I also assume that good projects are expected to be profitable to risk-neutral investors, i.e. that $E(z \mid g)>1$, where $E(z \mid g)$ represents the expected value of $z$ conditional on the project being good.

Let $B(\bullet)$ represent the cumulative distribution of $\widetilde{z}$, i.e. the probability that $z \leq \widetilde{z}$ for a bad project, and let $b(z)$ represent the probability density function of $z$ for bad projects. I also assume that $b(z)>0$ for all $z \epsilon[0, \bar{z}]$.

Returns on good projects exhibit first-order stochastic dominance over bad projects

$$
B(\widetilde{z})>G(\widetilde{z})
$$

for all $\widetilde{z}$. It follows that $E(z \mid g)>E(z \mid b)$.

If the project is liquidated after the first period, its return is equal to $l$, where $l<1$. I assume that conditional on a project being identified as bad, creditors prefer liquidation to rolling over their debt claims. The formal condition implied level of project realization, that would merely add an additional set of outcomes where the project realization, and not the minimum consumption level determined consumption. this would complicate the analysis, but not lead to any qualitative differences. 
by this assumption is shown below. I term this refusal to roll over short-term debt an "insolvency run" because liquidation is the profit-maximizing decision for creditors.

However, in good states, the expected returns from rolling over debt at adequate contractual rates are higher than the returns from liquidation, if all other creditors also choose to roll over their debt. I assume that sequential service holds, so that even in good states a creditor would not choose to roll over his claims given that the project is to be liquidated, since creditors who refused to roll over debts would share all of the proceeds of liquidation, and the returns to creditors who rolled over their claims would equal 0 .

There are then two possible equilibria in good states, one where all creditors privately roll over their debt claims, and one where a run takes place and no creditor rolls over his debt claims. Following the literature [e.g. Jeanne (2000)], I model the decision whether or not to roll over loans in good states as depending on the realization of a sunspot parameter. Let $\rho$ represent the probability that all creditors refuse to roll over short-term debt when projects are good. I term this outcome a "sunspot run" on the country, because the project ends up being liquidated despite the fact that it would be solvent if a run failed to take place. ${ }^{6}$

The realization of project type is assumed to be observable to only the representative creditor and borrower. ${ }^{7}$ In particular, the ILLR does not know the state of nature, only whether or not a run has taken place. This asymmetry of information can be motivated by the notion that creditors specialize in the countries to which they lend, and are likely to obtain superior information about conditions prevailing within a country. However, the ILLR is assumed to guarantee a large

${ }^{6} \mathrm{Zhu}$ (2000) demonstrates that allowing creditors to remove their claims sequentially can eliminate the possibility of bad sunspot equilibria.

${ }^{7}$ This assumption of full information across creditors allows for the multiplicity of equilibria. Morris and Shin (1999) and Goldstein and Pauzner (2000) demonstrate that lack of common knowledge among creditors may eliminate this multiplicity. 
number of borrowing countries, and hence know little about prevailing conditions within any individual debtor country, modeled here as lacking information about the realization of project type. ${ }^{8}$

At the end of the first period, loans come due. At this stage, creditors decide whether or not to roll over their existing obligations. If creditors choose to roll over the debt, the project continues to its completion. Let $r_{2}$ represent the interest rate charged by private creditors on rolled over debt.

If private creditors do not roll over the debt themselves, the ILLR is assumed to be able to act as a coordinator of private lending. The ILLR may offer to roll over a share $\lambda$ of outstanding short-term debt $\lambda \epsilon(0,1)$, conditional on creditors rolling over the remaining $(1-\lambda)$ share at a stated contractual interest rate. There is a participation constraint, which is derived below, which ensures that involvement in the relending package is voluntary ex-ante. Creditors are assumed to be able to commit ex-ante to a relending package with ILLR participation. Let $\widehat{r}_{2}$ represent one plus the interest rate charged on debt by the ILLR.

On completion of the project, if the debtor is solvent, creditors earn the full face value of their debt obligations. If the debtor is insolvent, monitoring takes place and the assets of the debtor are shared among the creditors according to their share of initial credit extensions. Monitoring costs are assumed to be proportional to debt claims.

\footnotetext{
${ }^{8}$ The extreme information asymmetry assumption, that the ILLR never is aware about bad state realizations, could be eased to allow a share of solvency based runs to take place under full information without changing the qualitative results. In these outcomes, the ILLR would also prefer liquidation if its loss function mirrored the sum of creditor profits. The qualitative analysis of the states where there was an information asymmetry would change little.
} 


\section{Terms of private debt rollovers}

I first solve for the terms at which private creditors are willing to roll over their outstanding debt obligations. Private creditors are assumed to be competitive, which implies that there are a large number of creditors which specialize in lending to each debtor nation. I model the interaction between a debtor and her private creditors in terms of a representative creditor.

To determine the terms at which private creditors are willing to roll over their first-period loans, I work backwards from the payoffs subsequent to realization of project value. Let $z^{*}$ represent the total contractual obligation of the debtor at the end of the second period, given that the project has not been liquidated. $z^{*}$ satisfies

$$
z^{*}=r_{1} r_{2}
$$

Since sovereignty rules out negative income from the project, the debtor is solvent if and only if $z \geq z^{*}$.

If the debtor is solvent, creditors earn the face value of their outstanding obligations. If the debtor is insolvent, costly state verification (CSV) is assumed to occur, as in the standard CSV model. ${ }^{9} \quad$ Debtors are assumed to earn their minimum, or 0 . Creditors earn the proceeds of the project net of monitoring costs, or $(z-\delta) \cdot{ }^{10}$

I next move to solve the terms at which debt would be rolled over at the end of period 1. Define $\Lambda_{g}$ as the net expected return on private rolled-over shortterm lending conditional on the project being good and creditors believing that

\footnotetext{
${ }^{9}$ For example, see Gale and Hellwig (1985) and Williamson (1986).

${ }^{10}$ Monitoring costs are assumed to be of sufficient mangnitude that debt contracts are desirable ex-ante, as in Boyd and Smith (1999). Cooper and Ross (1998) and Alonso (1996) have shown in models with costly runs and no monitoring that banks may choose ex ante to limit depositors to "run-proof" contracts which would not match a standard debt contract.
} 
no sunspot run will take place. $\Lambda_{g}$ satisfies

$$
\Lambda_{g}=\int_{0}^{z^{*}}(z-\delta) g(z) d z+r_{1} r_{2} \int_{z^{*}}^{\bar{z}} g(z) d z-r_{1}
$$

Note that the relevant criterion for the representative creditor to roll over his debt is a return of $r_{1}$, his full contractual debt obligation, rather than $l$, the proceeds from liquidation. Since creditors are small, their beliefs about liquidation are invariant with respect to their individual relending decision, so that sequential service ensures that they would receive $r_{1}$ in the event that they refused to roll over their claims.

For the model to be non-trivial, it must be the case that conditional on learning that projects are "good," short-term creditors would be willing to roll over their loans if they believe that other creditors are also willing to roll over their short-term loans. If this condition is not met, liquidation would take place with certainty. Formally, this requires that a value of $r_{2}$ exists which satisfies $\Lambda_{g} \geq 0$ or

$$
\arg \max _{r_{2}}\left(\Lambda_{g}\right) \geq 0
$$

I therefore take this as a parameter restriction on $g(z)$. Intuitively, this restriction imples that the expected returns on good projects are sufficiently high that conditional on the project being good and in the absence of a run, there would be some positive rate of interest $r_{2}$ at which creditors would be willing to roll over their debts. I assume that competition among creditors drives expected profits on second-period lending to zero when debt is rolled over privately. ${ }^{11}$ Let $r_{2}^{*}$ represent the equilibrium interest rate on rolled-over debt. $r_{2}^{*}$ satisfies

$$
\left(\Lambda_{g} \mid r_{2}=r_{2}^{*}\right)=0
$$

\footnotetext{
${ }^{11}$ Recall that creditors are assumed to play competivitively and therefore are precluded from playing strategically against the ILLR. In particular, I do not allow a coalition of creditors to initiate a run on the debtor in order to trigger an ILLR bailout.
} 
I next turn to bad project outcomes. Define $\Lambda_{b}$ as the net expected return on rolling over debt conditional on the creditor finding out that the project is bad, but believing that the project is not liquidated. $\Lambda_{b}$ satisfies

$$
\Lambda_{b}=\int_{0}^{z^{*}}(z-\delta) b(z) d z+r_{1} r_{2} \int_{z^{*}}^{\bar{z}} b(z) d z-r_{1} .
$$

Recall the assumption above that creditors would choose not to roll over their debt claims conditional on their project being bad, even when the project is not liquidated. Formally, this assumption requires that $\Lambda_{b}<0$. I adopt this restriction. Of course, the representative creditor is aware that this condition also holds for all other creditors, so that subsequent to the project being identified as bad, a solvency run will take place. Again, I refer to the sequential service assumption as ensuring that given a solvency run, the representative creditor will refuse to roll over his debt claims.

In summary, if the realization of the project is good, and there is no sunspotbased run, short-term creditors will roll over their claims at interest rate $r_{2}^{*}$, according to equation (3.4). However, if the realization of the project is bad or a sunspot run occurs, creditors will refuse to roll over their short-term claims, preferring instead to take their share of the proceeds of the liquidated project.

\section{ILLR Bailouts}

An ILLR bailout offer is defined as a triple, $\left(\lambda, r_{2}, \widehat{r}_{2}\right)$, where the ILLR offers to roll over a share $\lambda, \lambda \epsilon[0,1]$ of the debtor's outstanding debt obligation $r_{1}$ at the end of the first period at contractual rate $\widehat{r}_{2}$ in return for the creditor rolling over the remaining $(1-\lambda)$ share of debt at contractual rate $r_{2}$.

I assume that the ILLR acts as a coordinator of relending to the debtor. In particular, I allow the short-term creditors to credibly commit to participating in a relending package with a $\lambda r_{1}$ contribution by the ILLR when participation is optimal for short-term creditors ex ante. Implicitly, this rules out a second 
"sunspot run" on the debtor, in which only the ILLR contributes to the package and the firm has to be liquidated anyhow. Ruling this out requires that the punishment for shirking on a commitment to participate in the relending package is sufficiently severe that defection is never chosen. I make this assumption without formally modeling the necessary punishment, but I note in passing that one motivation for an official ILLR to be able to coordinate a relending package that private agents could not is exactly this ability to sufficiently punish potential shirking by individual creditors.

I again work backwards from the payoffs subsequent to realization of project value. Let $\widehat{z}^{*}$ represent the debtors' contractual obligation under bailout offer $\left(\lambda, r_{2}, \widehat{r}_{2}\right) . \widehat{z}^{*}$ satisfies

$$
\widehat{z}^{*}=\lambda r_{1} \widehat{r}_{2}+(1-\lambda) r_{1} r_{2}
$$

The determination of final payoffs is the same as before. If the debtor is solvent, the ILLR and creditors all earn the face value of their outstanding claims. However, if the debtor is insolvent, costly state verification (CSV) occurs. Debtors again earn their minimum, 0 . The ILLR and creditors earn their shares of initial extended funds to the debtor, net of the fixed monitoring $\operatorname{cost} \delta$. The ILLR earns $\lambda(z-\delta)$ while creditors earn $(1-\lambda)(z-\delta)$.

I first evaluate the terms at which creditors would be willing to participate in the relending package. I assume that in the sub-game subsequent to a run on the debtor, the ILLR acts as a Stackelberg leader relative to the atomistic creditors. Recall that at this stage, the creditors are aware whether the project is good or bad, and hence whether the run is a sunspot-run or a solvency-run.

Define $\widehat{\Lambda}_{g}$ as the net expected return on participation in the relending package by creditors conditional on knowing that the project is good, and the terms offered by the ILLR. $\widehat{\Lambda}_{g}$ satisfies

$$
\widehat{\Lambda}_{g}=\lambda r_{1}+(1-\lambda)\left[\int_{0}^{\widehat{z}^{*}}(z-\delta) g(z) d z+r_{1} r_{2} \int_{\widehat{z}^{*}}^{\bar{z}} g(z) d z\right]-l
$$


There are some notable differences between $\Lambda_{g}$ and $\widehat{\Lambda}_{g}$. First, since the relending package is coordinated, the relevant opportunity cost of not participating is $l$, rather than $r_{1}$. Second, under the relending program the creditor fails to roll over a $\lambda$ share of his debt claims, since that portion is borne by the ILLR. Third, because there is more than one claimant on the debtor, it is no longer certain that the expected payoff to the representative creditor is decreasing in $\widehat{z}^{*}$, i.e. that the payoff is decreasing in the probability of bankruptcy. The reason is that if the terms of the ILLR are sufficiently generous relative to those charged by the creditors, i.e. if $\widehat{r}_{2}$ is sufficiently smaller than $r_{2}$, the private creditors may do better obtaining their share of the proceeds of the project net of the monitoring costs, i.e. their proceeds under default, than obtaining full payment on their contractual obligations.

The assumptions necessary to rule out this unlikely occurence are that the deadweight loss of default, $\delta$, is sufficiently large. The condition for the representative creditor is

$$
\delta \geq \lambda r_{1}\left(\widehat{r}_{2}-r_{2}\right)
$$

in the neighborhood of $\widehat{z}^{*}$. Given this condition, the representative creditor will only be willing to participate in the relending package if $\widehat{\Lambda}_{g} \geq 0$.

Define $\widehat{\Lambda}_{b}$ as the net expected return on participation in the relending package by creditors conditional on knowing that the project is bad, and the terms offered by the ILLR. $\widehat{\Lambda}_{b}$ satisfies

$$
\widehat{\Lambda}_{b}=\lambda r_{1}+(1-\lambda)\left[\int_{0}^{\widehat{z}^{*}}(z-\delta) b(z) d z+r_{1} r_{2} \int_{\widehat{z}^{*}}^{\bar{z}} b(z) d z\right]-l
$$

In bad states, creditors will only be willing to roll over their debts if $\widehat{\Lambda}_{b} \geq 0$. This leads to the following corollary

LEMMA 1: For any triple, $\lambda, \widehat{r}_{2}$, and $r_{2}, \widehat{\Lambda}_{g}>\widehat{\Lambda}_{b}$.

Proof: 
By equation (4.1), given $\lambda, \widehat{r}_{2}$, and $r_{2}$, the value of $\widehat{z}^{*}$ is invariant with the project realization. By equations (4.2) and (4.4), $\Lambda_{g}-\Lambda_{b}$ satisfies

$$
\begin{aligned}
\widehat{\Lambda}_{g}-\widehat{\Lambda}_{b} & =(1-\lambda)\left[\int_{0}^{\widehat{z}^{*}}(z-\delta)[g(z)-b(z)] d z+r_{1} r_{2} \int_{\widehat{z}^{*}}^{\bar{z}}[g(z)-b(z)] d z\right] \\
& >0
\end{aligned}
$$

since returns on good projects exhibit first-order stochastic dominance over bad projects and $r_{1} r_{2}>(z-\delta)$ in the neighborhood of $z^{*}$. This leads to Proposition 1 :

PROPOSITION 1: There exist values of $\lambda, \widehat{r}_{2}$, and $r_{2}$ which yield a separating equilibrium, i.e. which leave short-term creditors willing to participate in the relending package when projects are good, but unambiguously preferring liquidation when projects are bad.

A separating equilibrium emerges when $\widehat{\Lambda}_{g} \geq 0$ and $\widehat{\Lambda}_{b}<0$. Under those conditons, by definition, creditors will voluntarily participate in the relending package if the project is good, but will refuse participation if the project is bad. In particular, one such separating equilibrium emerges for $\widehat{\Lambda}_{g}=0$. Given that $\widehat{\Lambda}_{g}=0$, Corollary 1 implies that $\widehat{\Lambda}_{b}<0$. Consequently, we have a separating equilibrium.

I next turn to the expected returns to the ILLR from participation in the relending package. Given that the ILLR offers terms consistent with a separating equilibrium, it knows that its offer will only be accepted when the project is good. Let $\widehat{R}_{\text {sep }}$ represent the expected return to the ILLR under the relending program conditional on choosing terms consistent with a separating equilibrium. $\widehat{R}_{\text {sep }}$ satisfies

$$
\widehat{R}_{\text {sep }}=\left(\frac{\phi \rho}{\phi \rho+(1-\phi)}\right) \lambda\left[\int_{0}^{\widehat{z}^{*}}(z-\delta) g(z) d z+r_{1} \widehat{r}_{2} \int_{\widehat{z}^{*}}^{\bar{z}} g(z) d z-r_{1}\right] .
$$


This term is equal to the probability-weighted expected return on ILLR lending in good states, since the ILLR does not participate in relending in bad states under the separating equilibrium. Note that the relevant probability of a good state is that conditional on a run taking place, which differs from the unconditional probability of a good state.

As was the case for the creditor, a parameter restriction is necessary to insure that $\widehat{R}_{s e p}$ is decreasing in $\widehat{z}^{*}$. The condition for the ILLR is

$$
\delta \geq-(1-\lambda) r_{1}\left(\widehat{r}_{2}-r_{2}\right) .
$$

The special significance of a relending program which sets $\widehat{\Lambda}_{g}=0$ is examined in Proposition 2:

PROPOSITION 2: In the range where expected creditor revenues are increasing in $r_{2}$ and expected ILLR revenues are increasing in $\widehat{r}_{2}$, the separating equilibrium which maximizes returns from the ILLR's point of view is attained by choosing a relending package which sets $\widehat{\Lambda}_{g}=0$.

Proof:

Suppose that there is a triple on the frontier, $\widehat{\Lambda}_{g}=0$. I demonstrate in the appendix that $d \widehat{\Lambda}_{g} / d \widehat{r}_{2} \leq 0$, so the ILLR could not raise its own contractual interest rate without losing the vountary participation of creditors. Similarly, I demonstrate that $d \widehat{R} / d r_{2} \leq 0$, so the ILLR could not raise the creditor's contractual interest rate, without reducing its own rate of return. It follows that maximizing its own rate of return and leaving the relending program voluntary in the normal range where expected creditor revenues are increasing in $r_{2}$ and expected ILLR revenues are increasing in $\widehat{r}_{2}$ requires choosing a relending package which satisfies $\widehat{\Lambda}_{g}=0$.

However, our general functional forms do not allow us to determine the revenuemaximizing triple satisfying $\widehat{\Lambda}_{g}=0$ for a given value of $\lambda$ from the ILLR's point of view. We turn to specific functional forms to investigate that issue below. 
Finally, the conditions for pooling equilibria are discussed as Proposition 3:

PROPOSITION 3: There are two sets of pooling equilibria in the model. If relending terms are set such that $\widehat{\Lambda}_{g}<0$, there is a pooling equilibrium in which creditors refuse to participate in the relending package regardless of the state of nature, while if relending terms are set such that $\widehat{\Lambda}_{b} \geq 0$, there is a pooling equilibrium in which banks participate in the relending package regardless of the state of nature.

Proof:

Corollary 1 implies that if $\widehat{\Lambda}_{g}<0, \widehat{\Lambda}_{b}<0$ as well. Moreover Corollary 1 implies that if $\widehat{\Lambda}_{b}>0, \widehat{\Lambda}_{g}>0$ as well. These conditions therefore result in the pooling equilibria described in Proposition 3.

Let $\widehat{R}_{\text {pool }}$ represent the expected returns to the ILLR conditional on offering relending terms consistent with a pooling equilibrium in which creditors participate in the relending package regardless of the state of nature. ${ }^{12} \widehat{R}_{\text {pool }}$ satisfies

$$
\begin{aligned}
\widehat{R}_{\text {pool }}= & \left(\frac{\phi \rho \lambda}{\phi \rho+(1-\phi)}\right)\left[\int_{0}^{\widehat{z}^{*}}(z-\delta) g(z) d z+r_{1} \widehat{r}_{2} \int_{\widehat{z}^{*}}^{\bar{z}} g(z) d z\right] \\
& +\left(\frac{(1-\phi) \lambda}{\phi \rho+(1-\phi)}\right)\left[\int_{0}^{\widehat{z}^{*}}(z-\delta) b(z) d z+r_{1} \widehat{r}_{2} \int_{\widehat{z}^{*}}^{\bar{z}} b(z) d z\right]-\lambda r_{1} .
\end{aligned}
$$

One can see that $\widehat{R}_{\text {pool }}$ is equal to the probability-weighted sum of expected returns in good and bad states, conditional on a run taking place.

\section{First-period lending rates}

I close the model by finding the condition for first-period lending rates. As creditors place a non-zero probability of a run at the end of the first period, the equilibrium value of $r_{1}$ will be affected by the expected response of the ILLR.

\footnotetext{
${ }^{12}$ The returns are obviously zero to the ILLR from offering terms which yields a pooling equilibrium in which creditors always refuse to participate in the relending package.
} 
I first consider the case where the ILLR chooses a lending policy consistent with a separating equilibium. Let $E\left(\lambda, \widehat{r}_{2}, r_{2}\right)$ represent the expected values of $\lambda, \widehat{r}_{2}, r_{2}$ offered by the ILLR's bailout package. Under a separating equilibrium, a relending package will only be accepted in the event of a good state and a sunspot run, which has probability $\phi \rho$. With probability $(1-\phi)$, the project is bad. Under the separating equilibrium, there is no bailout and the project is liquidated. Creditors receive their share of the project's liquidation value in this case. With probability $\phi(1-\rho)$, the project is good and no sunspot run takes place. Competition among creditors insures that no additional expected profits are earned on new lending, so the return on first-period lending is simply $r_{1}$. The expected returns on first-period lending therefore satisfy:

$$
E\left(R_{\text {sep }}\right) \equiv \phi(1-\rho) r_{1}+\phi \rho E\left[\widehat{\Lambda}_{g}+l\right]+(1-\phi) l-1=0
$$

in equilibrium due to competition among creditors, where $R_{\text {sep }}$ represents the expected return to private creditors when the ILLR is expected to offer a contract consistent with the separating equilibrium.

In contrast, suppose that in the event of a run the ILLR is expected to choose a sufficiently generous relending package that generates a pooling equilibrium in which creditors participate in the relending package regardless of the state of nature. As before, with probability $\phi(1-\rho)$, the project is good and no sunspot run takes place. Creditors expect to earn $r_{1}$. Also as before, with probability $\phi \rho$, the project is good but a sunspot run takes place. These runs result in ILLR intervention and relending. However, with probability $(1-\phi)$, the project is again bad, but creditors participate in the relending package. The expected returns to first-period lending therefore satisfy:

$$
\begin{aligned}
E\left(R_{\text {relending }}\right) & \equiv \phi(1-\rho) r_{1}+\phi \rho E\left[\widehat{\Lambda}_{g}+l\right]+(1-\phi) E\left[\widehat{\Lambda}_{b}+l\right]-1 \\
& =0
\end{aligned}
$$

in equilibrium due to competition among creditors, where $R_{\text {relending }}$ represents the 
expected return to private creditors when the ILLR is expected to offer a contract consistent with the pooling equilibrium with relending.

Finally, suppose that in the event of a run the ILLR chooses a sufficiently meager relending package which yields a pooling equilibrium in which creditors refuse the relending package regardless of the state of nature. As before, with probability $\phi(1-\rho)$, the project is good and no sunspot run takes place. Creditors again expect to earn $r_{1}$. As in the separating equilibrium, with probability $(1-\phi)$, the project is bad and there is no bailout and the project is liquidated. However, with probability $\phi \rho$, the project is good and a sunspot run takes place, but the relending package offered is refused, resulting in liquidation of the project. The expected payoff to first-period lending in this case satisfies

$$
E\left(R_{\text {no-relending }}\right) \equiv \phi(1-\rho) r_{1}+[\phi \rho+(1-\phi)] l-1=0
$$

where $R_{n o-\text { relending }}$ represents the expected return to private creditors when the ILLR is expected to offer a contract consistent with the pooling equilibrium with no relending.

By equations (5.1), (5.2), and (5.3), it is clear that $r_{1}$ will depend on the anticipated response of the ILLR. Indeed, it can be seen by inspection that creditors will charge the lowest initial interest rate if they anticipate the ILLR offering terms which will support a pooling equilibrium with relending in the event of runs and the highest interest rates if they anticipate the ILLR offering terms which yield a pooling equilibrium with no relending in the event of runs. The interest rates charged under the separating equilibrium will lie between these.

A special case arises when the ILLR chooses a relending package which leaves creditors indifferent between participation in the relending package and no participation, i.e. which sets $E\left[\widehat{\Lambda}_{g}\right]=0$. By equations (5.1) and (5.3), it can be seen that the expected return on lending under a separating equilibrium with $E\left[\widehat{\Lambda}_{g}\right]=0$ is equal to that under the pooling equilibrium with no relending. This leads to our final Proposition. 
PROPOSITION 4: The equilibrium first period interest rate conditional on expected participation by the ILLR in a relending package which sets $\widehat{\Lambda}_{g}=0$ is equal to that which would emerge in the absence of ILLR intervention.

Proof:

By equation (5.1), if $E\left[\widehat{\Lambda}_{g}\right]=0, r_{1}$ satisfies

$$
\phi(1-\rho) r_{1}+[\phi \rho+(1-\phi)] l-1=0
$$

which is identical to the equilibrium condition for $r_{1}$ given the pooling equilibrium with no relending. Of course, the ILLR offering to participate in a relending package at terms which are refused is equivalent to its not intervening at all. Consequently, the first-period interest rate that emerges when the ILLR offers relending terms which leaves creditors indifferent between participation and nonparticipation in the relending package is equivalent to that which would prevail without ILLR participation.

This final result is relevant because of the concerns in the literature about moral hazard issues surrounding lender of last resort activity. Our analysis demonstrates that when the ILLR offers relending packages which are only acceptable in good states and are on the toughest possible terms, intervention in the separating equilibrium form described above has no distortionary impact on first-period lending.

As the terms for the ILLR get even easier, however, i.e. when $\widehat{\Lambda}_{g}>0$, the first period interest rate will fall as the terms faced by creditors become easier and $r_{1}$ falls. This can be easily seen by totally differentiating (5.1) with respect to $r_{1}$ and $r_{2}$ :

$$
\left(\frac{d r_{1}}{d r_{2}} \mid s e p\right)=-\frac{\rho \frac{\partial \widehat{\Lambda}_{g}}{\partial r_{2}}}{(1-\rho)+\rho \frac{\partial \widehat{\Lambda}_{g}}{\partial r_{1}}}<0
$$

when $\partial \widehat{\Lambda}_{g} / \partial r_{1}>0$ and $\partial \widehat{\Lambda}_{g} / \partial r_{2}>0$. These terms are ambiguous in sign; their derivations are shown in the appendix. However, we would expect both terms to 
be positive in normal ranges.

As the ILLR terms ease, the next change takes place when $\widehat{\Lambda}_{b}$ enters the positive range and we move to the pooling relending equilibrium. It can be seen by inspection of equations (5.1) and (5.2) that $r_{1}$ is continuous at $\widehat{\Lambda}_{b}=0$. However, as $\widehat{\Lambda}_{b}$ moves into the positive range, the sensitivity to a change in ILLR terms will change. Totally differentiating (5.2) with respect to $r_{1}$ and $r_{2}$ yields:

$$
\left(\frac{d r_{1}}{d r_{2}} \mid \text { pool, relending }\right)=-\frac{\phi \rho \frac{\partial \widehat{\Lambda}_{g}}{\partial r_{2}}+(1-\phi) \frac{\partial \widehat{\Lambda}_{b}}{\partial r_{2}}}{\phi(1-\rho)+\phi \rho \frac{\partial \widehat{\Lambda}_{g}}{\partial r_{1}}+(1-\phi) \frac{\partial \widehat{\Lambda}_{b}}{\partial r_{1}}}<0
$$

when $\partial \widehat{\Lambda}_{j} / \partial r_{1}>0$ and $\partial \widehat{\Lambda}_{j} / \partial r_{2}>0(j=g, b)$. These terms are also ambiguous in sign and their derivations are also shown in the appendix. Given the above conditions, easing the rescheduling terms beyond levels consistent with $\widehat{\Lambda}_{g}=0$ will reduce first period lending rates.

\section{Simulations}

In this section, I turn to simulations to examine the implications of various responses by the ILLR to a run of unknown origin. To examine the results of the model, I must adopt an explicit distribution for $z$. For good projects, let $z$ be distributed uniform on the interval $z \epsilon\left[0, \bar{z}_{g}\right]$. For bad projects, let $z$ be distributed uniform on the interval $z \epsilon\left[0, \bar{z}_{b}\right]$, where $\bar{z}_{g}>\bar{z}_{b}$ to provide the stochastic dominance of good projects. For the parameters used in the model, I set $\rho=0.3$, $\phi=0.9, \delta=0.4, l=0.7, \bar{z}_{g}=5$, and $\bar{z}_{b}=2$. I then run three simulations. In each, one of the terms of the relending package is allowed to vary while the other two terms are held fixed. When they are held fixed, the terms of the relending contract are given the following values: $r_{2}=0.5, \lambda=0.4$, and $\widehat{r}_{2}=1.5$. These parameters all fall in the interior of the separating equilibrium range when their variable is allowed to vary holding the others fixed. 
I assume that the ILLR's reponse to a run is correctly anticipated by all agents when setting initial interst rates. This would seem to be the most plausible assumption to make regardless of the commitment capacity of the ILLR, but it precludes the possibility that the ILLR could mislead agents by deviating from its expected behavior subsequent to a run.

By the distributional assumption for $z$ and equation (4.2), $\widehat{\Lambda}_{g}$ is equal to

$$
\widehat{\Lambda}_{g}=\lambda r_{1}+(1-\lambda)\left[\left(\frac{\widehat{z}^{*}}{\bar{z}_{g}}\right)\left(\frac{\widehat{z}^{*}}{2}-\delta\right)+r_{1} r_{2}\left(\frac{\bar{z}_{g}-\widehat{z}^{*}}{\bar{z}_{g}}\right)\right]-l .
$$

By equation (4.4), $\widehat{\Lambda}_{b}$ is equal to

$$
\widehat{\Lambda}_{b}=\lambda r_{1}+(1-\lambda)\left[\left(\frac{\widehat{z}^{*}}{\bar{z}_{b}}\right)\left(\frac{\widehat{z}^{*}}{2}-\delta\right)+r_{1} r_{2}\left(\frac{\bar{z}_{b}-\widehat{z}^{*}}{\bar{z}_{b}}\right)\right]-l .
$$

While the model does not posit a loss function for the ILLR, we can still investigate the expected profitability of ILLR lending under various values of $r_{2}$. Obviously, under the pooling equilibrium with no relending the expected return to the ILLR is equal to zero. We can then calculate the expected returns to the ILLR under the separating and pooling equilibria with relending by substituting our distributional assumptions for $z$ in good and bad states into equations (4.5) and (4.6).

The expected returns to the ILLR for a variety of values of $r_{2}$ holding $\lambda$ and $\widehat{r}_{2}$ fixed are shown in Figure 2.1. Separating and pooling equilibria are first identified by finding the values of $r_{2}$ which correspond to $\widehat{\Lambda}_{g}=0$ and $\widehat{\Lambda}_{b}=0$ in equations (6.1) and (6.2). The expected returns for each value of $r_{2}$ are then calculated based on whether an offer with that value of $r_{2}$ will generate the separating or pooling equilibria. The process is then repeated for a variety of values for $\lambda$ in Figure 2.2 and for a variety of values of $\widehat{r}_{2}$ in Figure 2.3.

In Figure 2.1, we start with an expected return of 0 under the pooling equilibrium with no relending at very low levels of $r_{2}$. There is then a discrete upward 
shift in the expected return as $r_{2}$ moves across the value consistent with $\widehat{\Lambda}_{g}=0$, i.e. as we move from the pooling equilibrium with no relending to the separating equilibrium.

Within values consistent with the separating equilibrium, the expected return to the ILLR declines as $r_{2}$ is increased. These increases in the values of $r_{2}$ increase the probability of default, without afffecting the ILLR's contractual terms of repayment in non-default states, so they have an adverse impact on the expected returns of the ILLR. These increases also represent the allocation of some portion of the rents associated with relending to the creditor. Recall that the creditor is indifferent by definition at $\widehat{\Lambda}_{g}=0$ between accepting and rejecting the relending proposal. The offer consistent with $\widehat{\Lambda}_{g}=0$ is then that which recovers all of the rents associated with relending for the ILLR, which is why it represents the maximum attainable expected return to the ILLR.

At this value, the simulation shows that $E\left(R_{\text {relending }}\right) \equiv 0.0752$ and the initial contractual interest rate given this expected response of the ILLR is equal to 1.173. With the posited value of $\lambda=0.4$, this corresponds to an expected rate of return for the ILLR on its relending outlay equal to $16 \%$ when it retains all of the rents associated with avoiding liquidation of the debtor.

As $r_{2}$ moves across the value consistent with $\widehat{\Lambda}_{b}=0$, there is a discrete downward movement in the expected return to the ILLR, as we move from the separating to the pooling equilibrium with relending. The discrete change in the expected return here reflects the fact that the ILLR no longer knows that it is only lending in good states, so that the expected return changes to the probability-weighted sum of payoffs in good and bad states.

Figure 2.2 repeats the exercise for increasing $\lambda$ from 0.2 to 0.5 . Again, there is a discrete upward shift in the expected return to the ILLR as we cross the value of $\lambda$ consistent with $\widehat{\Lambda}_{g}=0$ and attain the separating equilibrium. However, within the separating equilibrium the results show that $\widehat{R}$ is increasing in $\lambda$. 
Expected returns to the ILLR are then maximized when $\lambda$ is at the maximum level consistent with the separating equilibrium, i.e. that consistent with $\widehat{\Lambda}_{b}=0$. Beyond this point, we move to the pooling equilibrium with relending. There is a discrete decline in the expected return to the ILLR, again reflecting that it is now also participating in the relending package in bad states.

Note that this exercise only implies that expected returns are maximized at $\widehat{\Lambda}_{b}=0$ for a given value of $r_{2}$. In particular, the results in Figure 2.2 are not contradictory with Proposition 2, which states that the ILLR's maximum return will be at the point consistent with $\widehat{\Lambda}_{g}=0$. To verify this, I took the value of $\lambda$ consistent with maximizing ILLR returns in Figure $2.2(\lambda=0.452)$, and redid the Figure 2.1 simulation for various values of $r_{2}$. The pattern was similar to that shown in Figure 2.1, with the maximum of $\widehat{R}$ at the value of $r_{2}$ consistent with $\widehat{\Lambda}_{g}=0$. This value of $\widehat{R}(0.084)$, was larger than the shown maxima in either Figure 2.1 or Figure 2.2. Therefore, when both $\lambda$ and $r_{2}$ were allowed to vary, the maximum was again at $\widehat{\Lambda}_{g}=0$, as predicted by Proposition 2 .

Finally, Figure 2.3 plots values of $\widehat{R}$ as $\widehat{r}_{2}$ varies from 0.1 to 2 . The simulation does not include a pooling range with no relending. At the values of $\widehat{r}_{2}$ considered, it is always the case that $\widehat{\Lambda}_{g}>0$. This result primarily stems from the fact that $\lambda=0.4$, which leaves the probability of default relatively insensitive to the ILLR's contractual interest rate. However, we again see the familiar pattern as $\widehat{r}_{2}$ is reduced sufficiently to attain the pooling equilibrium with relending. There is a discrete downward movement in the expected return to the ILLR as we move from the separating to the pooling equilibrium.

These simulations clearly reflect the positive impact on expected ILLR returns from tailoring the relending package to generate a separating equilibrium. Because liquidation is undesirable in good states, moving from no relending to a separating relending package creates rents which are partially captured in the form the positive expected returns to the ILLR. Moving on to the pooling re- 
lending equilibrium, however, leads to relending in bad states as well, reducing the expected returns from ILLR participation in the relending package.

Within the separating equilibrium range, our simulations gave intuitive advice about the type of contract which would maximize ILLR returns. ILLR returns were at their maxima within the separating range when $r_{2}$ was as low as possible and when $\widehat{r}_{2}$ was as high as possible. Moreover, given that these two parameters were fixed to values which left the relending package profitable to the ILLR, ILLR returns were maximized when $\lambda$ was as large as possible under the separating equilibrium.

\section{Conclusion and Extensions}

This paper considers the implications of allowing for fundamentals-based runs in addition to the sunspot runs considered in the literature for international lender of last resort activity. I introduce a model where foreign creditors possess superior information to the ILLR concerning the underlying prospects of investment in place in the debtor nation. The analysis demonstrates that when information asymmetries of this type arise, the ILLR is likely to do better, in the sense of avoiding undesirable bailouts or liquidations, by tailoring the offered terms of a relending package to obtain a separating equilibrium where the relending package is only accepted when offers are good.

This analysis indicates that adverse selection issues can provide an alternative motivation for Bagehot's Principle that lender of last resort activity should take place at high rates. In the model above, achieving the separating equilibrium requires that the ILLR charge a sufficiently high rate of interest relative to that offered to private creditors under the relending package to preclude creditors from accepting the package in bad states.

The model introduced here is highly stylized and leaves room for future ex- 
tensions. First, the optimal level of participation of the ILLR in the relending package, $\lambda$, was not endogenously determined. Doing so would have required taking a stand on the loss function of the ILLR, which was avoided in this paper as a modeling strategy.

Second, the model above does not address the merits of long vs. short-term debt, a central issue in the literature [e.g. Rodrik and Velasco (1999), Jeanne (2000)]. Under the separating equilibrium above, long term debt is dominated by short-term debt because the only liquidations which take place are optimal ones. Short-term debt has the advantage of the option to liquidate subsequent to the realization of the state of nature. Nevertheless, long-term debt could play a role if the debtor nation was risk averse, even in the presence of an ILLR. Its role would be as a form of insurance, increasing debtor consumption in bad states of nature where relending does not take place. 


\section{APPENDIX}

Differentiating $\widehat{\Lambda}_{j}(j=g, b)$ with respect to $\lambda, r_{2}$, and $\widehat{r}_{2}$ :

Differentiating $\widehat{\Lambda}_{j}(j=g, b)$ with respect to $\lambda$ yields:

$$
\begin{aligned}
\frac{d \widehat{\Lambda}_{j}}{d \lambda}= & r_{1}-\left[\int_{0}^{\widehat{z}^{*}}(z-\delta) j(z) d z+r_{1} r_{2} \int_{\widehat{z}^{*}}^{\bar{z}} j(z) d z\right] \\
& +(1-\lambda) \frac{d \widehat{z}^{*}}{d \lambda}\left(\widehat{z}^{*}-\delta-r_{1} r_{2}\right) j\left(\widehat{z}^{*}\right)
\end{aligned}
$$

The last term is negative when $\widehat{r}_{2} \geq r_{2}$.

Differentiating $\widehat{\Lambda}_{j}(j=g, b)$ with respect to $r_{2}$ yields:

$$
\frac{d \widehat{\Lambda}_{j}}{d r_{2}}=(1-\lambda)\left[r_{1} \int_{\widehat{z}^{*}}^{\bar{z}} j(z) d z+(1-\lambda)^{2} r_{1}\left(\widehat{z}^{*}-\delta-r_{1} r_{2}\right) j\left(\widehat{z}^{*}\right)\right]
$$

Differentiating $\widehat{\Lambda}_{g}(j=g, b)$ with respect to $\widehat{r}_{2}$ yields

$$
\frac{d \widehat{\Lambda}_{j}}{d \widehat{r}_{2}}=(1-\lambda) \lambda r_{1}\left(\widehat{z}^{*}-\delta-r_{1} r_{2}\right) j\left(\widehat{z}^{*}\right)<0
$$

\subsection{Differentiating $\widehat{R}$ with respect to $\lambda, r_{2}$, and $\widehat{r}_{2}$ :}

Differentiating $\widehat{R}$ with respect to $\lambda$ yields

$$
\frac{d \widehat{R}}{d \lambda}=\left[\int_{0}^{\widehat{z}^{*}}(z-\delta) g(z) d z+r_{1} \widehat{r}_{2} \int_{\widehat{z}^{*}}^{\bar{z}} g(z) d z-r_{1}\right]+\lambda \frac{d \widehat{z}^{*}}{d \lambda}\left(\widehat{z}^{*}-\delta-r_{1} \widehat{r}_{2}\right) g\left(\widehat{z}^{*}\right) .
$$

The last term is negative when $\widehat{r}_{2} \geq r_{2}$.

Differentiating $\widehat{R}$ with respect to $r_{2}$ yields

$$
\frac{d \widehat{R}}{d r_{2}}=\lambda\left[(1-\lambda) r_{1}\left(\widehat{z}^{*}-\delta-r_{1} \widehat{r}_{2}\right) g\left(\widehat{z}^{*}\right)\right]<0
$$

Differentiating $\widehat{R}$ with respect to $\widehat{r}_{2}$ yields

$$
\frac{d \widehat{R}}{d r_{2}}=\lambda\left[r_{1} \int_{\widehat{z}^{*}}^{\bar{z}} b(z) d z+\lambda r_{1}\left(\widehat{z}^{*}-\delta-r_{1} \widehat{r}_{2}\right) g\left(\widehat{z}^{*}\right)\right]
$$




\section{References}

[1] Aghion, Philippe, Patrick Bolton, and Steven Fries (1999), "Optimal Design of Bank Bailouts: The Case of Transition Economies," J ournal of International and Theoretical Economics, 155, 51-70.

[2] Allen, Franklin and Douglas Gale (1998), "Optimal Financial Crises," J ournal of Finance, 53(4), 1245-1284.

[3] Alonso, Irasema (1996), "On Avoiding Bank Runs," J ournal of Monetary Economics, 37, 73-87.

[4] Berger, Allen, Sally M. Davies, and Mark J. Flannery (2000), "Comparig Market and Supervisory Assessments of Bank Performance: Who Knows What When?," J ournal of Money, Credit and Banking, 32(3) Pt. 2, 641-667.

[5] Boyd, John H. and Bruce D. Smith (1999), "The Use of Debt and Equity in Optimal Financial Contracts," J ournal of Financial Intermediation, 8, 270-316.

[6] Chang, Roberto, and Andrés Velasco (1999), "Liquidity Crises in Emerging Markets: Theory and Policy," N.B.E.R. Macroeconomics Annual, (MIT Press: Cambridge), 11-78.

[7] Chang, Roberto, and Andrés Velasco (2000), "Banks, Debt Maturity, and Financial Crises," J ournal of International Economics, 51, 169-194.

[8] Chari, V. V. and Ravi Jagannathan (1988), "Banking Panics, Information, and Rational Expectations Equilibrium," J ournal of F inance, 43(3), 749-761.

[9] Cooper, Russell, and Thomas W. Ross (1998), "Bank Runs: Liquidity Costs and Investment Distortions," J ournal of M onetary E conomics, 41, 27-38.

[10] Diamond, Douglas, and P. Dybvig (1983), "Bank Runs, Deposit Insurance, and Liquidity," J ournal of Political Economy, 91, 401-419.

[11] Eichengreen, Barry, Toward a New International Financial Architecture, Institute for International Economics, Washington D.C., (1999).

[12] Freixas, Xavier, Bruno M. Parigi, and Jean-Charles Rochet (2000), "Systemic Risk, Interbank Relations, and Liquidity Provision by the Central Bank," J ournal of Money, Credit and Banking, 32(3) Pt. 2, 611-638. 
[13] Gale, Douglas and Martin Hellwig (1985), "Incentive-Compatible Debt Contracts: The One-Period Problem," Review of Economic Studies, 52, 647-663.

[14] Goldfajn, Ilan, and Rodrigo Valdés (1997), "Capital Flows and the Twin Crises: The Role of Liquidity," International Monetary Fund Working Paper no. WP $/ 97 / 87$.

[15] Goldstein, Itay and Ady Pauzner (2000), "Demand Deposit Cintracts and the Probability of Bank Runs," mimeo, Tel Aviv University, April.

[16] Goodhart, Charles A. E. (1999), "Myths About the Lender of Last Resort," International Finance, 2:3, 339-360.

[17] Goodhart, Charles A. E. and Haizhou Huang (1999), "A Model of the Lender of Last Resort," International Monetary Fund Working Paper no. WP/99/39.

[18] Jacklin, Charles J. and Sudipto Bhattacharya (1988), "Distinguishing Panics and Information-Based Bank Runs: Welfare and Policy Implications," J ournal of Political Economy, 96(3), 568-592.

[19] Jeanne, Olivier (2000), "Debt Maturity and the Global Financial Architecture," mimeo, International Monetary Fund.

[20] Kumar, Manmohan S., Paul Masson, and Marcus Miller (2000), "Global financial Crises: Institutions and Incentive," International Monetary Fund Working Paper no. WP/00/105.

[21] Marchesi, Silvia, and Jonathan P. Thomas (1999), "IMF Conditionality as a Screening Device," Economic J ournal, 109, C111-C125.

[22] Morris, Stephen, and Hyun Song Shin (1999), "Coordination Risk and the Price of Debt," mimeo.

[23] Rodrik, Dani, and Andrés Velasco (1999), "Short-Term Capital Flows," N.B.E.R. Working Paper no. 7364, September.

[24] Williamson, Stephen D., "Costly Monitoring, Loan contracts, and Equilibrium Credit Rationing," J ournal of Monetary E conomics, 18, 159-179.

[25] Zhu, Haibin (2000), "Bank Runs without Self-Fulfilling Prophecies," mimeo, Duke University, November. 
Figure 1

Extensive Form

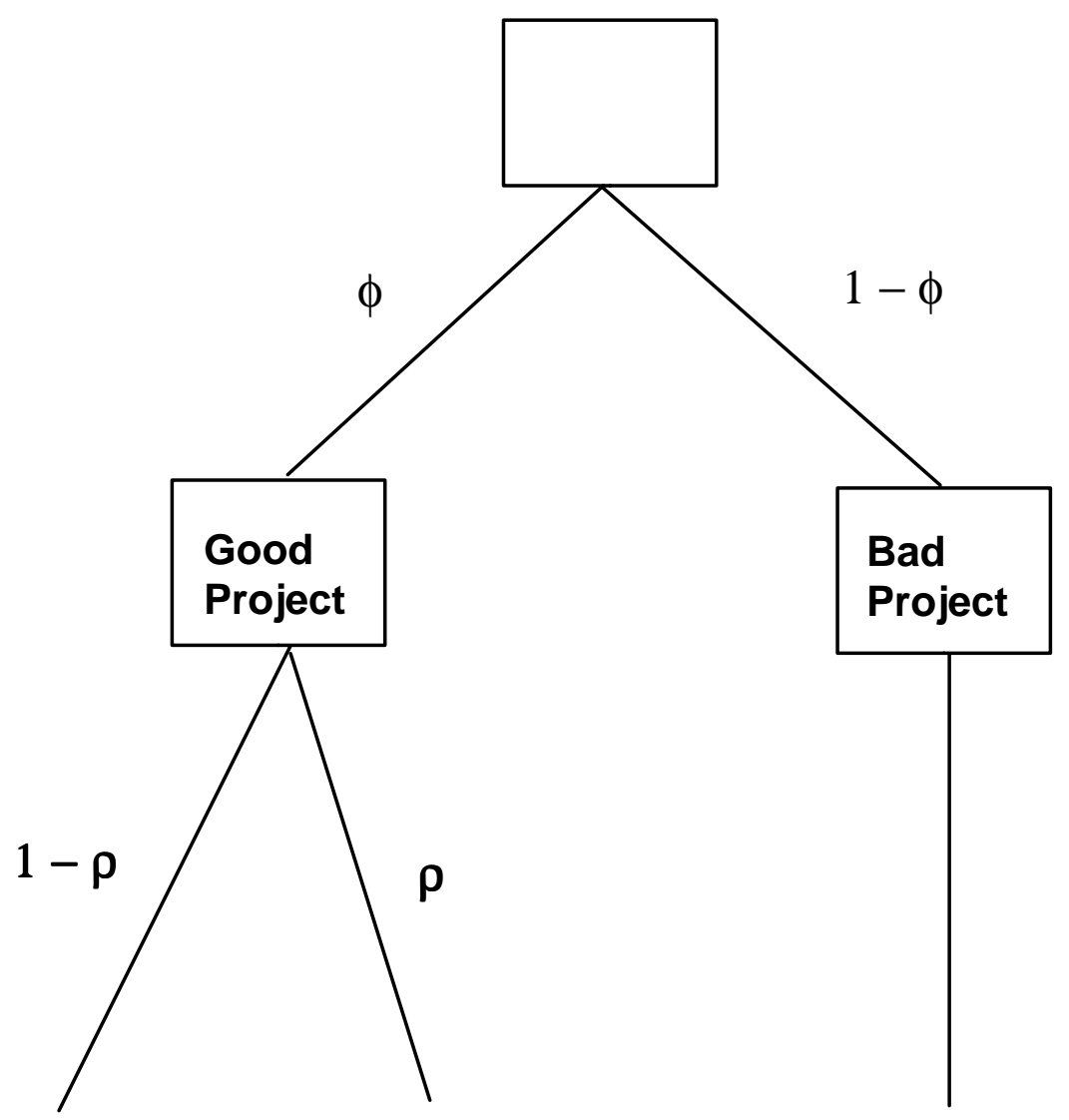

No Run

Run

Run 
Figure 2

Expected Return to ILLR
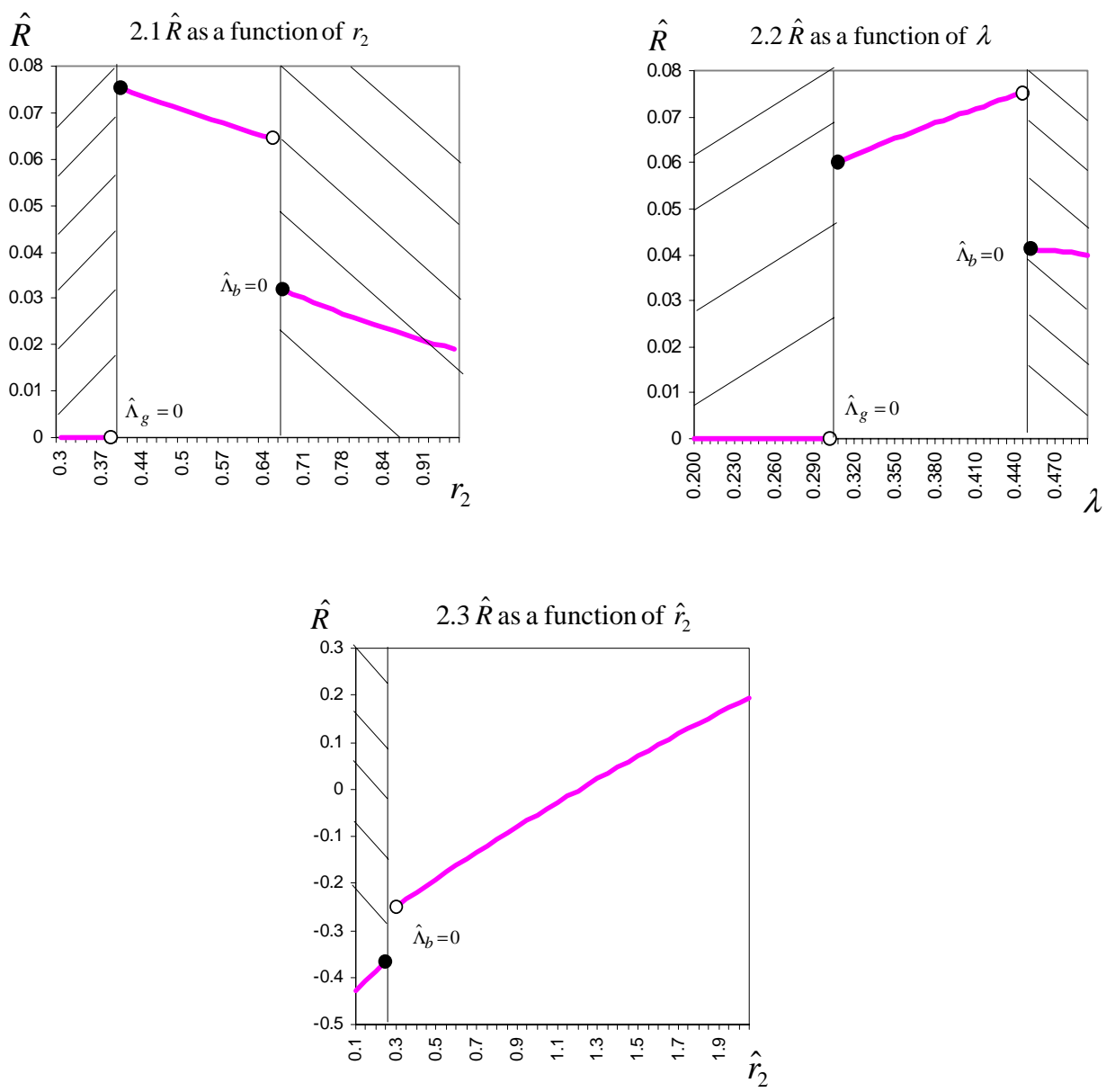

- Pooling equilibrium, no relending.

- Separating equilibrium.

- Pooling equilibrium, relending in both states.

Note $: \hat{R}$ represents the net expected return to the ILLR. $r_{2}, \lambda$, and $\hat{r}_{2}$

represents the contractual return to private creditors, the share of

relending by the ILLR, and the contractural return to the ILLR respectiv -

ely. For Figure 2.1, $\lambda=0.4$ and $\hat{r}_{2}=1.5$. For Figure 2.2, $r_{2}=0.5$ and $\hat{r}_{2}=1.5$.

For Figure 2.3, $r_{2}=0.5$ and $\lambda=0.4$. See text for other parameter values. 